\title{
Critical Care Practice : Bangladesh Perspective
}

The concept of intensive care unit was first percept during the evolution of nursing by Florence Nightingale in 1850s. She first showed that clustering \& intensive monitoring of severely wounded patient makes the outcome better. In 1950s anesthesiologist Dr. Peter Safar implemented the concept of advanced life support by keeping the patient sedated and ventilated. Dr. Safar is considered as the pioneer in the practice of Critical Care Medicine. The polio epidemic in Europe in that era served as a boost to the medical science and lead to development to practically feasible mechanical ventilation. In 1953, Bjorn Ibsen converted a municipal hospital classroom in Copenhagen what later became the first ICU in the world. The introduction of mechanical ventilation reduced the mortality rate of polio respiratory failure from $90 \%$ to $40 \%$ at that time. ${ }^{1}$

Now a day's ICUs are concerned with critically ill patients who need advanced support system to sustain life that may give enough time to recover from the primary illness. With the advent of technologies newer machines are coming and we can take over, manipulate and supplement the work of more and more organ systems. The complexity, multi disciplinary involvement and ethical dilemmas make the ICU service unique. Specifically Trained personnel to serve the critically ill patients are a must to run an ICU properly. ${ }^{2}$ It is the most expensive, resource intensive, technologically advanced and diverse area of medical science that is relentlessly evolving since its inception.

National Institute of Cardiovascular Diseases (NICVD) pioneered the ICU service in Bangladesh in 1980. Over the past 3 decades the practice expanded and in a study done by Department of Critical Care Medicine, BIRDEM hospital in 2007 found total number of ICU beds were 424 in 40 ICUs in Bangladesh. Most of them were open ICU (85\%) and $68 \%$ were run by anesthesiologists. ${ }^{3}$ Since then the number of ICU beds increased to approximately 700 beds now. With the exception of handful state of the art modern hospitals, the quality of service in majority of ICUs are inadequate and poor. Profound lack of trained manpower, high burden of cost, reluctance of standardizing and monitoring authorities and lack of support system all contribute to the suffering of critically ill patients. ${ }^{4}$

Critical Care Medicine has been recognized as an independent specialty since last 3-4 decades in North America and Europe. Research, evolution and shaping of the specialty has taken place and matured over time by the patients and doctors of its own territory. Academic and educational programs are at place for doctors, nurses and technicians. A separate entity of specialized nurses known as 'respiratory therapist' also has evolved. The respiratory therapists are mostly concerned with airway support, maintenance and handling of specialized equipments including ventilators. Comparing our status in Bangladesh, the academic endeavor has started in 2007 by Dhaka University, as they have started to offer MD (CCM). Department of CCM of BIRDEM General Hospital and Dhaka Medical College Hospital are enrolling 14 post graduate students each year. So far we have only one physician with postgraduate qualification of MD (CCM) out of these courses. Bangladesh should have at least 5000 ICU beds and 600 post graduate qualified CCM specialist to support the ICUs properly. These numbers are based on the approximate total number of general hospital beds of 75000 as per Bangladesh Bureau of Statistics 2010 estimation. $^{5}$

CCM has just started evolving in Bangladesh, the academic course offered in this specialty and establishment of Bangladesh Society of Critical Care Medicine are two major milestones in the path. There are many challenges standing and many more to face in the future in the way to uniform and standard critical care facility in the country. Inadequate trained manpower, high cost and poor quality are the major issues in the forefront. The government run facilities offer free service but the quality of care suffers tremendously from grossly insufficient funding. Privately run ICUs are much more expensive compared to the government one but unfortunately only few are able to maintain the minimum quality care. The expense of average critical care admission is way beyond the reach of average income people of the country and there is no existing support system to cover the extra costs.

Scarcity of trained physician and nurses cannot be overemphasized by any means. For the time being short certificate courses to train doctors along with offering trained doctors special incentive may ease the problem earlier.

To maintain and improve quality of ICU services proper monitoring is a must. The authority may collaborate with the society to set up specific rules and requirements for establishing an ICU and impose the rules of minimum technological, instrumental support along with manpower requirement to run an ICU. Standard of care should be set and strictly imposed by authorities like BMDC and Directorate of Health.

The economic burden on people for availing ICU service can be shared by government in the form of subsidy. Philanthropist and various organizations should come forward with their social responsibility to share the burden. Privately managed health insurance can offer a sustainable solution which is a rarity in Bangladesh.

All these effort to improve the service needs to be orchestrated with great mastery and the Government 
should be the key player in the decision making. Coordinated works of ministry of health, BMDC, BMA, BSCCM and various involved organizations can make the service better within existing framework and direct the development in a fruitful track.

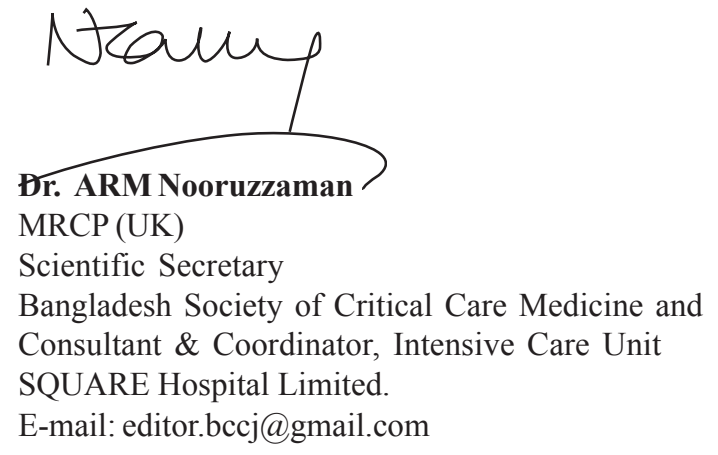

\section{References}

1. Bennett D, Bion J. ABC of Intensive Care. BMJ 1999; 318 : 1468-70.

2. Ewart GW, Marcus L, Gaba MM et al. The Critical Care Medicine crisis - a call for federal action. Chest 2004; 125 : 1518-21.

3. Faruq MO, Ahsan ASMA, Fatema K, Ahmed F et a. An audit of Intensive Care Services in Bangladesh. Ibrahim Medical College Journal 2010; 4(1): 13-16.

4. Faruq MO. Critical Care Medicine in Bangladesh: Evolution and Challenges. Key note presentation at the regional conference of Bangladesh Society of Critical Care Medicine at Chittagong 2011.

5. Bangladesh Bureau of Statistics. Statistical Pocket Book of Bangladesh 2009, 2010: p375. 